RESENHA

\title{
Interação entre empresas e instituições de Ciência e Tecnologia - o caso do sistema farmacêutico de inovação brasileiro
}

\section{Julia Paranhos}

Rio de Janeiro, RJ, Brasil: Editora da Universidade do Estado do Rio de Janeiro, 2012.

\section{Márcia Siqueira Rapini*}

Departamento de Economia da Universidade Federal de Minas Gerais (UFMG), Belo Horizonte (MG), Brasil.

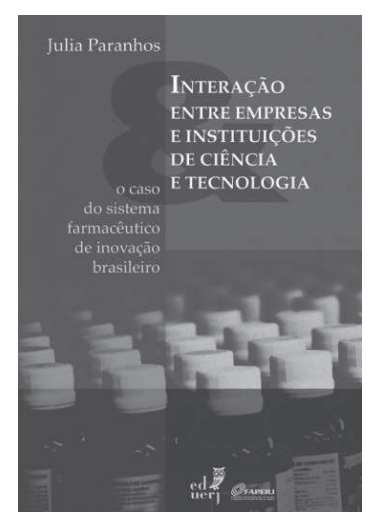

O livro de Júlia Paranhos, Interação entre empresas e instituiçôes de Ciência e Tecnologia - o caso do sistema farmacêutico de inovação brasileiro, fruto da sua tese de doutorado no IE/UFRJ, insere-se em esforços recentes no sentido de avançar na compreensão desta temática no Brasil. Trata-se de uma leitura recomendada e obrigatória para todos que se interessam pelo tema, em especial pelo setor farmacêutico. Além de apresentar evidências empíricas recentes sobre interação universidade-empresa no setor farmacêutico, Júlia enriquece sua análise ao transcrever trechos das entrevistas com os atores. Em suma, a autora adentra a "caixa-preta" da interação universidade-empresa em um setor tradicionalmente classificado como baseado na ciência (PAVITT, 1984).

A fim de permitir certa comparabilidade, ainda que reconhecendo suas diferenças, Julia apresenta, no capítulo 2, o sistema farmacêutico de inovação no Reino Unido. Isto foi uma escolha acertada, pois permite inferir, ao final, que muitas das debilidades e dificuldades à interação universidade-empresa no Brasil partem de deficiências do lado de quem inova, ou seja, das empresas. Vale a pena destacar a inversão proposta pela autora já no título do livro: interação entre empresas e ICTs.

* E-mail: rapini@cedeplar.ufmg.br 
Julia optou por manter o foco na empresa, lócus do processo de inovação, contrariamente à terminologia mais utilizada na literatura brasileira (interação universidade-empresa), bem como ampliou sua investigação, analisando a interação não apenas com universidades, mas também com outros agentes geradores de conhecimento e pesquisa, utilizando a terminologia Instituições de Ciência e Tecnologia (ICT). ${ }^{1}$

Júlia faz um trabalho de folego, pois, além de utilizar dados secundários para caracterizar as distintas interfaces da cooperação empresa-ICT no Brasil e no Reino Unido no setor farmacêutico, entrevistou ao todo 51 agentes. A autora construiu um roteiro de entrevista amplo, com a finalidade de inferir a visão sistêmica do processo interação, entrevistando empresas, universidades, governo e outros agentes relevantes do setor. ${ }^{2}$ A riqueza dos trechos transcritos das entrevistas sinaliza para a relevância de mesclar análises quantitativas e qualitativas, em qualquer estudo que vise ampliar a comprensão de fenômenos reais e contribuir para a proposição de políticas.

O livro é dividido em duas partes. A primeira é composta por três capítulos e reúne os arcabouços teórico e empírico brasileiro e inglês. O capítulo 1, teórico, merece ser destacado, pois, em vez de partir de uma teoria do relacionamento empresa-ICT, a autora apresenta as três principais abordagens: da hélice tripla (ETZKOWITZ; LEYDESDORFF, 1995), na qual a universidade está no centro do processo de inovação; da universidade como ator do desenvolvimento social (DAGNINO, 2003; AROCENA; SUTZ, 2003); e a abordagem de SNI, em que as universidades são importantes na construção de competências ${ }^{3}$ e realizam pesquisas fundamentais para o processo de inovação nas empresas. Apesar de se propor, na introdução, a utilizar as três abordagens, a que a autora emprega nas análises subsequentes é a terceira, exatamente por sugerir uma visão sistêmica do processo de inovação. Contudo, as duas anteriores são recuperadas na conclusão, quando ela afirma que "não existem papéis diferentes para as ICTs nas economias periféricas, [...] mas existem momentos diferentes no desenvolvimento dos sistemas de inovação e, com isso, atores com papéis diferenciados" (p. 326).

O segundo capítulo reúne dois tópicos que mereciam ser tratados em separado: transformações das atividades de P\&D no setor farmacêutico; e o sistema farmacêutico de inovação inglês. No primeiro, a descrição da evolução das atividades de $\mathrm{P} \& \mathrm{D}$ no setor é fundamental, pois explicita que a aproximação com universidades foi

1 Seguiu a terminologia utilizada na Lei de Inovação (10.973).

2 Agências de inovação de universidades, incubadoras, laboratórios públicos, empresas de consultoria, etc.

3 Educação e treinamento, criação de capital humano, produção e reprodução de técnicas, aprendizado individual (EDQUIST, 2005). 
parte de estratégias das empresas para "ampliar suas fontes de conhecimento, reduzir riscos, conseguir financiamento e aumentar suas oportunidades inovativas" (p. 63), ainda que em alguns países esta proximidade tenha sido construída historicamente em alguns setores desde a origem (ROSENBERG; NELSON, 1994; MEYER-KRAMER; SCHMOCH, 1998). A relevância das transformações das atividades de P\&D para explicar o aumento da cooperação com ICTs no setor farmacêutico mais que justifica a criação de outro capítulo.

Já a descrição do sistema farmacêutico de inovação inglês ocorre ao longo do livro - parte no capítulo 2 (seção 2.3) e parte no capítulo 9 (seções 9.1 e 9.2). As informações apresentadas justificam a escolha do Reino Unido para a comparação com o Brasil: importância do setor farmacêutico no país e resultado positivo da cooperação empresa-ICT. O SNI inglês possui especificidades que favoreceram o desenvolvimento do sistema de inovação farmacêutico, tais como a consolidação de um forte sistema de inovação em saúde no país, revertendo na criação de um ambiente propício à inovação e em uma significativa estrutura de financiamento à pesquisa biomédica tanto em universidades quanto em empresas. $\mathrm{O}$ resultado foi a gestação de empresas farmacêuticas inovadoras globais, com expressivas atividades de P\&D no país e no exterior, bem como o estabelecimento de ICTs com capacidade científica reconhecida mundialmente (e habilidade de transbordar o conhecimento para a sociedade).

No terceiro capítulo, Júlia apresenta o desenvolvimento do sistema farmacêutico de inovação brasileiro e o relacionamento empresas-ICTs, descrevendo detalhadamente os atores - empresas, ICTs e governo (como regulador, financiador e legislador) - que foram objeto de suas entrevistas. O setor farmacêutico brasileiro passou por mudanças consideráveis nos últimos anos, podendo-se destacar o crescimento das empresas nacionais a partir da produção de medicamentos genéricos. Mas, diferentemente do Reino Unido, no Brasil as empresas nacionais são pouco inovadoras, registrando baixos investimentos em atividades de P\&D. As ICTs, apesar de possuírem reconhecida competência em diversas áreas do conhecimento, carecem de orçamento para a realização de pesquisas, bem como de regras para a interação com empresas.

A segunda parte do livro é composta por seis capítulos que apresentam a análise e os resultados das pesquisas de campo realizadas entre 2008 e 2010, no Brasil e Reino Unido, esta segunda feita durante o período do doutorado "sanduíche" no SPRU. No capítulo 4, Júlia caracteriza os atores entrevistados: empresas (farmacêuticas nacionais e multinacionais, de pesquisa, de insumos farmacêuticos, CRO - contract 
research organizations - e laboratórios públicos), grupos de pesquisa e demais atores (agências de inovação de universidades, instituições de fomento e governo).

Nos próximos dois capítulos, a interação empresa-ICT é apresentada na visão das empresas e pequisadores (capítulo 5) e dos demais atores (capítulo 6), abrangendo as principais atividades colaborativas, motivação, obstáculos, facilitadores, papel dos NITs e das fundaçôes universitárias, financiamento e propriedade intelectual. Muitos dos resultados encontrados na interação universidade-empresa para o sistema farmacêutico brasileiro são os mesmos identificados na literatura internacional, merecendo destaque o que é específico ao setor e/ou ao Brasil.

Entre os obstáculos específicos ao setor no Brasil que surgiram na pesquisa, está a ausência de escalonamento nas moléculas oferecidas pelos pesquisadores às empresas. Esta etapa não existe nas empresas brasileiras, uma vez que as mesmas fazem pouca pesquisa. Logo, para o caso brasileiro, seria importante haver um terceiro ator especializado nas atividades de escalonamento para "completar o gap entre a ICT e a empresa" (p. 172).

Outro aspecto relevante, podendo ser considerado obstáculo, por um lado, e facilitador, por outro, refere-se à existência de profissionais nas empresas com conhecimento sobre o meio acadêmico, para facilitar o diálogo empresa-ICT. A falta de pessoal qualificado para a inovação aparece, na Pintec 2008, pesquisa realizada pelo IBGE, como a terceira dificuldade mais frequente à inovação. Não é surpresa que tenha aparecido na pesquisa de Júlia, mas é preocupante não ser ainda alvo da política de inovação.

Um último fator que tem vários impactos na interação empresa-ICT é a ausência de orçamento nas universidades brasileiras para a pesquisa, ainda que o professor a tenha entre suas atividades obrigatórias. A atividade de pesquisa é financiada com recursos públicos competitivos ou por meio da parceria com empresas (em muitos casos também a partir de editais competitivos). De acordo com a autora, esta pode ser "uma das razóes para que os pesquisadores frequentemente transformem seus projetos de parceria em pesquisa básica. Essa tendência, bastante criticada pelas empresas, faz com que os projetos de parceria financiados pelo governo muitas vezes acabem distantes de qualquer visão de uso e aplicação comercial” (p. 304). Diferentemente, no Reino Unido, as universidades dispõem de orçamento para pesquisa e o recurso da empresa "pode realmente ser considerado um recurso extra" (p. 304).

O capítulo 7 é dedicado à avaliação da atuação do governo e do aparato institucional-regulatório do ponto de vista das empresas e de outros agentes do setor. Não é novidade a desarticulação dos órgãos do governo, bem como a burocracia da 
Anvisa e sua sobreposição à atuação do Inpi na concessão de patentes de fármacos. A evidência mais relevante refere-se ao financiamento do governo que, apesar de importante, não é suficiente para promover a inovação e o desenvolvimento, de acordo com opinião dos atores. As empresas que conseguem financiamento do governo são aquelas que já possuem um projeto de inovação, de forma que os instrumentos parecem não ser eficazes no fomento para que novas empresas comecem a inovar. De acordo com uma empresa, "todos os editais que ganhamos são produtos que a gente já vinha trabalhando, já tem todas as informações" (p. 189).

O capítulo 8 distingue-se dos demais por tratar das perspectivas para o setor na visão dos atores em relação: às estratégias empresariais; à biodiversidade e biotecnologia como alternativas de diversificação; e ao mercado externo. Neste sentido, esta parte do livro foge dos temas tradicionais analisados nos estudos desta temática, cumprindo papel de subsidiar políticas de fomento ao setor. É possível observar consenso dos entrevistados quanto à necessidade de mudança de estratégia das empresas, que devem ser mais ousadas em suas estratégias de inovação. O mesmo, contudo, não é observado quanto ao aproveitamento da biotecnologia e biodiversidade, cujas opiniôes divergem e sinalizam para a necessidade de uma atuação forte do governo para que possam ser uma possibilidade real de diversificação. Quanto ao mercado externo, os entraves são ainda maiores que as oportunidades.

O capítulo 9 culmina o trabalho de Júlia, uma vez que a autora busca unir a discussão teórica com a síntese dos resultados encontrados nas pesquisas, comparando o Brasil ao Reino Unido. É um importante esforço que ilustra a riqueza de comparar, mesmo que diferentes sistemas de inovação, pois ficam evidentes aspectos que são específicos a cada um. Duas diferenças merecem ser destacadas. A primeira refere-se às áreas de conhecimento em que as empresas buscam a colaboração dos pesquisadores das ICTs. Nos dois países, as áreas principais são química e farmácia. A diferença está nas áreas que ocupam a segunda posição: farmacologia, biologia e fisiologia (da área de saúde), no Reino Unido; e medicina (da área de saúde) e engenharia, no Brasil. Esta última é importante na etapa de escalonamento de moléculas (mencionada anteriormente). Ademais, a biologia é relevante no Reino Unido indicando movimento das empresas em desenvolver medicamentos de base biotecnológica, o que ainda não está acontecendo no Brasil.

A segunda diferença aqui ressaltada refere-se aos fatores que motivam a interação. No Brasil, as empresas nacionais mencionaram, como importantes fatores motivacionais, a infraestrutura dos laboratórios e a possibilidade de financiamento do governo para a parceria. Já no Reino Unido a motivação encontra-se na busca 
de capacitação nas ICTs, acesso a talentos, acesso a formadores de opinião e divisão de risco. As diferenças estão claramente relacionadas às estratégias de inovação das empresas de cada país, que se refletem na existência ou não de instalações, bem como de dotação orçamentária para a realização de P\&D.

Mais estudos de casos e setoriais precisam ser realizados para avançar na compreensão da dinâmica da interação universidade-empresa (ou empresa-universidade!) no Brasil. Que o livro seja, pois, uma inspiração para outros pesquisadores.

\section{Referências bibliográficas}

EDQUIST, C. Systems of innovation - perspectives and challenges. In: FAGERBERG, J.; MOWERY, D.; NELSON, R. R. The Oxford handbook of innovation. Oxford: Oxford University Press, 2005.

MEYER-KRAMER, F.; SCHMOCH, U. Science-based technologies: university- industry interactions in four fields. Research Policy, v. 27, n. 8, p. 835-851, 1998.

PAVITT, K. Sectoral patterns of technical change: towards a taxonomy and a theory. Research Policy, v. 13, n. 6, p.343-373, 1984.

ROSENBERG, N.; NELSON, R. R. American universities and technical advance in industry. Research Policy, v. 23, p. 323-348, 1994. 